\title{
Microcrédito e Microempreendedor: o caso do Crediamigo na região do Vale do Jequitinhonha, em Minas Gerais
}

\section{Microcredit and Micro-Entrepreneur: the case of Crediamigo in Vale do Jequitinhonha, in Minas Gerais}

\author{
Leandro Martins Vieira \\ Mestrando em Administração (Finanças) pela Universidade Federal de Minas Gerais (UFMG), Participa do Grupo de Pesquisa EICIS da UFMG \\ leandrovieira@globo.com \\ http://lattes.cnpq.br/0878691565022717
}

Francisco Vidal Barbosa

Pós-doutorado em Gestão de empresas de base tecnológica - setor de biotecnologia pela Harvard University em Cambridge - EUA. Professor titular da Universidade Federal de Minas Gerais e professor visitante da University of Applied Sciences Schmalkalden (2002), Alemanha. fvberlim@gmail.com http://lattes.cnpq.br/5115477440886635

Resumo: O microcrédito tem despertado o interesse de governantes devido a sua suposta capacidade de combater a pobreza e de criar oportunidades de desenvolvimento econômico em áreas tradicionalmente pouco favorecidas economicamente. Todavia pouco se tem estudado a respeito dos microempreendimentos que utilizam este tipo de financiamento. Este trabalho busca esclarecer como o microcrédito influencia a promoção do empreendedorismo no Vale do Jequitinhonha. Para explicitar este fenômeno, foi realizado um survey com microempreendedores que foram atendidos pelo Crediamigo. Os dados coletados foram agrupados por meio da cluster analysis. A análise dos dados permitiu constatar que o microcrédito exerce uma influência positiva na lucratividade e na geração de fluxo de caixa nos negócios, uma vez que permite a formação de capital de giro em condições melhores do que aquelas que possuíam anteriormente. Porém, a influência positiva não foi encontrada na geração de novos empregos, já que grande parcela é composta por trabalhadores individuais. Palavras-chave: Microcrédito, Vale do Jequitinhonha, Microempreendedores, Cluster Analysis

Abstract: Microcredit has awakened the interest of rulers due to its supposed capacity to fight poverty and create economic development opportunities in areas traditionally less-favored economically. However, little has been studied about the microenterprises that utilize this type of financing. This paper seeks to clarify how microcredit influences the promotion of entrepreneurship in Vale do Jequitinhonha. In order to explain this phenomenon, a survey with micro entrepreneurs that were served by Crediamigo was conducted. The collected data was grouped by means of cluster analysis. The data analysis made it possible to verify that microcredit has a positive influence upon the profitability and cash flow emanation in businesses, once it provides the means for the generation of working capital in better conditions. Still, this positive influence relation was not observed when it came to job creation, since a big part of it is composed of individual workers. Keywords: Microcredit, Vale do Jequitinhonha, Micro-Entrepreneurs, Cluster Analysis

Texto completo em português: http://www.apgs.ufv.br Full text in Portuguese: http://www.apgs.ufv.br

\section{INTRODUÇÃo}

Diversas regiões do Brasil sofrem com a falta de emprego e de oportunidades de desenvolvimento econômico. Uma das causas desse fenômeno está relacionada ao racionamento de crédito para pessoas que desejam empreender, mas não conseguem financiar seus negócios por não possuírem garantias tangíveis para oferecer às instituições financeiras. O microcrédito tem sido uma ferramenta bastante utilizada para a promoção econômica e social em países em desenvolvimento, principalmente após a criação do Grameen Bank, em Bangladesh, em 1983 (Neri, 2008). Vários fóruns de discussões envolvendo governos e Organizações não governamentais (ONGs) vêm se interessando progressivamente pelo tema. Diversos trabalhos foram publicados no Brasil sobre microcrédito, como os de Barone (2008), Neri (2008) e Martins (2008). Esse interesse ocorre devido à possibilidade de melhorar as condições de vida dos menos favorecidos, de possibilitar o aquecimento econômico e de promover maior circulação financeira. Iniciativas como o Crediamigo e a atuação de agências de desenvolvimento regionais e bancos estatais brasileiros têm, desde a década de 2000, investido cada vez mais na promoção do microcrédito, buscando a sustentabilidade financeira dos programas e tentando romper com a necessidade de subsídios públicos, orientação que levou as iniciativas que ocorreram em décadas anteriores ao fracasso (Neri, 2008).

Apesar de os investimentos em programas de microcrédito serem considerados uma importante ferramenta para o desenvolvimento econômico e o combate ao desemprego em regiões pobres, não se sabe se a utilização desses recursos ocorre de forma correta nem quais seriam seus impactos nos pequenos negócios.

Para tentar resolver esse problema, o Banco do Nordeste do Brasil (BNB) criou em 1997 o Crediamigo, sendo considerado o maior programa de microcrédito produtivo e orientado da América Latina (BNB, 2014) e englobando atualmente dois terços do mercado nacional. Além do tamanho, o programa também é reconhecido pela qualidade, tendo sido escolhido pelo Banco Interamericano de Desenvolvimento (BID) em 2008 como ganhador do prêmio Excelência em Microfinanças (Neri, 2012). Atualmente, o Crediamigo atua em todos os nove estados da região Nordeste do Brasil, bem como nos estados de Minas Gerais, Espírito Santo e

Correspondência/Correspondence: Leandro Martins Vieira. Universidade Federal de Minas Gerais. Av. Pres. Antônio Carlos, 6627 - Pampulha, Belo Horizonte - MG, Brasil leandrovieira@globo.com 
Rio de Janeiro, atendendo a 1.992 municípios em 426 unidades de atendimento (BNB, 2013).

O Crediamigo oferece um serviço que atende os clientes nas proximidades do local onde desenvolvem seus negócios (Neri, 2008). É um programa de microcrédito e atua como instituição de primeiro piso. O processo de concessão de crédito busca empregar a menor burocracia possível. O capital é fornecido em até sete dias uteis. Os valores iniciais variam entre $R \$ 100,00$ e $R \$ 15.000,00$ por cliente, conforme o tamanho do empreendimento. Suas renovações têm como valor máximo possível $R \$ 15.000,00$, dependendo do produto, da capacidade de pagamento e da estrutura do negócio, permanecendo esse valor como endividamento máximo do cliente (BNB, 2014). O produto mais utilizado é o capital de giro mediante aval solidário. A média dos financiamentos é de aproximadamente $\mathrm{R} \$ 1.600,00$ (BNB, 2013).

Dentre as unidades do Crediamigo, a unidade Capelinha, objeto deste estudo, conta atualmente com uma equipe de 11 assessores de crédito, 4 administrativos e 1 coordenador. Atende um total de 8.365 clientes ativos (31 de outubro de 2014), com uma carteira ativa de $\mathrm{R} \$ 9.863 .825,00$, o que dá uma média de 760 usuários por assessor, ou $\mathrm{R} \$ 1.179,00$ de financiamento por pessoa.

A filial atende os municípios de Capelinha, Diamantina, Itamarandiba, Turmalina, Veredinha, Angelândia, Aricanduva, Água Boa, Setubinha e Santa Maria do Suassuí, sendo que os três últimos estão na área geográfica do Vale do Mucuri. Em Diamantina existe um posto de atendimento permanente, porém nas outras cidades o atendimento ocorre geralmente em um local cedido pela prefeitura municipal e ocorre uma vez por semana.

Além da quantidade de atendimento e de desembolsos, é importante notar a qualidade da carteira da filial. Atualmente, a inadimplência no Crediamigo Capelinha é de $R \$ 64.502,04$, o que representa $0,65 \%$ do capital investido. O referido percentual é inferior à média do programa (0,85\%) (BNB, 2013, p. 38). Os incrementos foram também significativos, tendo um aumento de 1.510 novos clientes de janeiro a outubro de 2014 .

Entretanto, mesmo com o aparente sucesso do Crediamigo, o microcrédito - no âmbito das microfinanças - não é uma solução mágica capaz de resolver todos os problemas relacionados à pobreza e à inexistência de oportunidades de trabalho e de geração de renda. De acordo com Hulme e Mosley (1996) o microcrédito pode ajudar a combater a pobreza, mas a grande maioria dos programas atuais é menos eficiente do que poderia ser. Em alguns casos, devido à concessão equivocada de recursos, pode até mesmo agravar a pobreza de indivíduos ou comunidades (Hulme \& Mosley, 1996; Rogaly, 1996 e Wright, 1999).

O debate sobre os benefícios ou não do microcrédito é relativamente novo e não conclusivo. A maioria dos estudos relacionados se concentra nas IMFs ou na melhora da condição de vida dos tomadores de recursos. Este estudo visa avaliar a maneira como o microcrédito pode influenciar o desenvolvimento dos micronegócios no Vale do Jequitinhonha.

É relevante compreender a utilização e aplicação dos recursos do microcrédito não só pelo potencial de transformação na vida das famílias tomadoras de recursos, mas também pela capacidade de geração de empregos e desenvolvimento das comunidades. Além disso, atua no sentido de fornecer indicadores que possam orientar as instituições financiadoras na maior efetividade de seus programas.

Diante dessa realidade surge a seguinte questão: como a disponibilidade do microcrédito influencia os microempreendimentos no Vale do Jequitinhonha?

\section{REFERENCIAL TEÓRICO}

\section{Crédito: aspectos conceituais e teóricos}

A promoção do crédito assume grande importância para o desenvolvimento socioeconômico de um país ou região. Silva (2006) destaca que existem evidências da concessão de crédito nas ruínas da antiga Babilônia, tendo sido encontrados registros de um compromisso firmado por um fazendeiro que deveria pagar juros para remunerar quem lhe concedera empréstimo até o período da colheita.

O crédito pode ser considerado como a entrega de um valor presente mediante uma promessa de pagamento (Silva, 2006) ou, segundo Schrickel (1995), vontade ou ato de alguém ceder parte do seu patrimônio a um terceiro, de forma que o pagamento das parcelas retorne integralmente após decorrido o tempo estipulado.

Ou seja, o crédito está associado à expectativa de retorno do valor cedido. Com isso, qualquer crédito está associado ao risco (Schrickel, 1995). Os bancos não são os únicos fornecedores de financiamento, mas sua atividade principal é a intermediação financeira, sendo responsáveis por colocar à disposição do cliente tomador certa quantia em forma de crédito, mediante a promessa de recebimento numa data futura (Figura 1) (Silva, 2006).

Figura 1: Representação do crédito

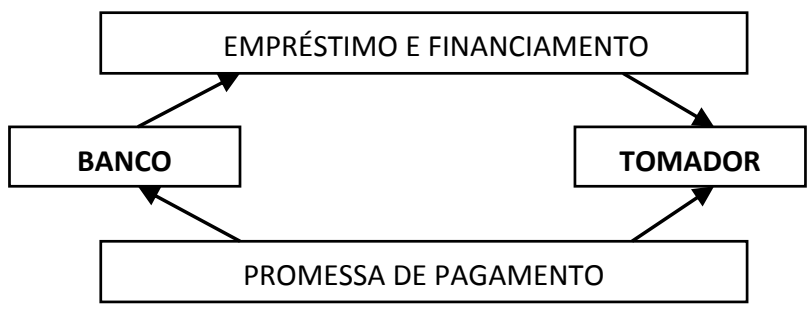

Fonte: Silva (2006 p. 39)

As instituições financeiras podem disponibilizar crédito tanto para pessoas físicas quanto para jurídicas. No primeiro caso, ajudam-nas a antecipar a compra de bens de consumo ou mesmo de bens duráveis, como moradia, por exemplo, assim permitindo o aquecimento da economia e o aumento dos níveis de emprego. No segundo caso, permitem a elas aumentar seu nível de atividade. Entretanto, a má utilização do crédito pode levar os indivíduos e as empresas a um elevado grau de endividamento, comprometendo a sua capacidade de pagamento ou mesmo a aceleração do consumo, pressionando os preços e gerando um processo inflacionário (Silva, 2006).

Silva (2006) explica que o crédito pode ser de grande importância para os diversos tipos de negócios, por exemplo no comércio, onde o financiamento atua como um facilitador da venda, permitindo ao consumidor adquirir um produto sem a necessidade 
de possuir no momento da compra o montante total necessário. 0 mesmo ocorre na indústria, que também se beneficia das linhas de crédito para a aquisição das máquinas e dos insumos necessários à produção.

\section{Riscos e suas tipologias}

Toda e qualquer operação de crédito está relacionada à existência de risco. Por mais criteriosa que possa ser realizada a análise do cliente para a liberação de recursos, a possibilidade de não pagamento jamais deve ser ignorada. No segmento bancário existem cinco grupos de riscos, conforme listados por Silva (2006): i) risco de mercado; ii) risco de crédito; iii) risco legal; iv) risco de liquidez; e v) risco de conjuntura. Esses ricos são aferidos por meio de uma série de modelos para mediar a probabilidade de inadimplência dos tomadores. Contudo, apesar da grande quantidade de variáveis utilizadas, as análises resultam em múltiplas dimensões de dados complexos, porém unicamente de caráter quantitativo (Chen \& Cheng, 2013).

Este trabalho, por focalizar o microcrédito, concentra-se principalmente no chamado "risco de crédito", ou seja, a probabilidade de que o pagamento não ocorra pode ser considerada como 1 (um) menos a esperança do recebimento (Silva, 2006). O maior risco que pode ocorrer numa operação de crédito é o desconhecimento sobre quem é o tomador e as aplicações que ele pretende fazer com os recursos (Schrickel, 1995).

No âmbito do risco intrínseco, geralmente são analisados os chamados "Cs do crédito". Essa análise permite verificar dois elementos fundamentais em que se baseiam a "confiança" na concessão de crédito: a) a vontade do devedor em liquidar suas obrigações conforme os termos contratados; b) a habilidade do tomador em assim fazê-lo (Schrickel, 1995). Nesses dois grupos, o caráter e a capacidade fazem parte do primeiro grupo; já o capital e as condições, do segundo grupo. Há, ainda, um quinto $C$, chamado de "colateral", que é complementar aos elementos anteriores.

Inserido no conceito do colateral está a questão das garantias. Elas existem para gerar um comprometimento pessoal ou patrimonial por parte do tomador e servir como um "pronto-socorro" para o intermediário financeiro, uma vez que este tem algo que possa ser tomado para ser usado como parte ou totalidade dos pagamentos não realizados.

\section{Assimetria de informação, restrição de crédito e colaterais alternativos}

O racionamento de crédito é um fenômeno percebido e bastante debatido nos meios acadêmicos (Hodgman, 1960). Isso contraria o princípio básico da economia de que, havendo equilíbrio entre oferta e demanda, os preços irão cair quando a demanda está baixa e subir quando há excesso de demanda, não havendo racionamento (Stiglitz \& Weiss, 1981). Entretanto, o racionamento de crédito existe e implica a abundante demanda por empréstimos. Com efeito, esse fato é atribuído a problemas de assimetria de informações entre demandantes e ofertantes de crédito (Neri, 2008). Isso pode levar ao aumento dos custos de monitoramento e controle dos tomadores, o que em alguns casos torna os custos inacessíveis ao público dos programas de microcrédito (Ghosh \& Van Tassel, 2013).

A definição da expressão racionamento de crédito está geralmente associada às seguintes circunstâncias: a) alguns solicitantes de crédito, mesmo possuindo características semelhantes a outros, não recebem empréstimos ainda que se predisponham a pagar uma taxa de juros maior; b) certos indivíduos, em determinada oferta de crédito, não o conseguem independente da taxa de juros, mas poderiam conseguir quando há uma oferta maior (Neri, 2008); c) alguns ou todos os tomadores recebem uma quantidade de recursos inferior à sua demanda (Jaffee \& Russell, 1976); d) alguns potenciais tomadores não solicitam empréstimos por conhecerem os custos de transação e a pouca probabilidade de obterem êxito (Bester, 1985).

A diminuição da assimetria de informação é um passo essencial para a promoção do crédito produtivo popular no Brasil, levando o financiamento a camadas menos favorecidas da população (Neri, 2008). A percepção desse problema levou instituições financeiras de desenvolvimento ligadas aos governos ou organismos internacionais a criar programas para preencher essa lacuna (Ribeiro \& Carvalho, 2006). Isso gerou a criação de duas vertentes. A primeira, ligada aos governos, que, mesmo buscando atender 0 público de baixa renda, mantinha os processos no que tange a garantias, solicitação de empréstimos e controles financeiros, tal como nos bancos tradicionais. Isso acabou afastando os potenciais tomadores que não se enquadravam nos pré-requisitos. A segunda, era representada por ONGs que possuíam um caráter unilateral no social, e não visava à sustentabilidade financeira dos programas (Instituto Brasileiro de Administração Municipal [IBAM], 2001).

Segundo Morduch (1999), os programas de financiamento com viés unicamente social não tiveram continuidade principalmente, devido às elevadas taxas de inadimplência, superiores a $50 \%$, aos elevados subsídios e aos desvios de verbas pelos governos.

A mudança no paradigma na atuação das instituições de financiamento ocorreu pela influência da linha de pensamento da chamada "Escola de Ohio", desenvolvida pela Universidade de Ohio, Estados Unidos, que inspirou os quadros do Banco Mundial e alterou a condução das políticas de crédito aos menos favorecidos (Ribeiro \& Carvalho, 2006). A ideia central consistia principalmente na crítica à atuação da ação estatal como instituição financiadora, defendendo a atuação do mercado e o fechamento de qualquer instituição financeira incapaz de gerar a sustentabilidade (Hulme \& Mosley, 2005).

Desenvolveu-se então um novo paradigma para as instituições de financiamento que se enquadram nas chamadas "instituições financeiras inovadoras", as quais comerciais podem desenvolverse, prestando serviços financeiros de forma rentável para população de baixa renda, sem subsídios, e alcançando o públicoalvo (Ribeiro \& Carvalho, 2006). Para isso ocorrer, é necessário diminuir a assimetria de informações e criar meios de garantir os empréstimos sem a necessidade de garantias físicas ou financeiras. Consequentemente, foram criados os "colaterais sociais", que consistem em prever outras formas de proteção contra a 
inadimplência, tendo no chamado "aval solidário" a forma mais conhecida (Lima, 2009).

O aval solidário consiste na formação de grupos de tomadores de empréstimos em que todos são responsáveis solidariamente por arcar com os compromissos perante a IMF. Caso um dos membros não cumpra a obrigação de pagamento, todos são penalizados. Entretanto, no caso de todas as regras contratuais forem seguidas, a totalidade dos participantes recebe os benefícios. Esta ferramenta dá a possibilidade de resolução do problema de seleção adversa, uma vez que só se formará uma equipe se houver confiança mútua entre os membros (Ribeiro \& Carvalho, 2006). Entretanto, isso pode se tornar um entrave para algumas instituições de microfinanças que não trabalham com essa metodologia, devido, principalmente, a questões culturais e à dificuldade de alguns tomadores de se estabelecerem elos de credibilidade (Lima, 2009).

Outra ferramenta bastante utilizada são os esquemas de empréstimos progressivos, em que os valores dos financiamentos aumentam à medida que há adimplência dos clientes (Lima, 2009). Os custos de transação são reduzidos, uma vez que o montante se eleva e a necessidade de monitoramento é reduzida na aquisição de novos empréstimos (Ribeiro \& Carvalho, 2006). Além disso, algumas instituições devolvem parte dos juros em caso de pagamentos pontuais, permitindo, assim, a redução da inadimplência e a possibilidade do tomador conseguir mais crédito.

Um ator bastante importante para o cumprimento dos objetivos das IMFs é o agente de crédito. Esse profissional é responsável por todas as etapas, desde o primeiro contato até a liquidação e renovação dos financiamentos (Ribeiro \& Carvalho, 2006). Ele acompanha os empreendimentos, verifica o fluxo caixa e a aplicação dos recursos e analisam a capacidade de pagamento dos tomadores. Com esse monitoramento, é possível reduzir o risco moral das instituições financeiras, bem como contribuir para uma melhor gestão dos empreendedores (Lima, 2009).

\section{Microcrédito e Microfinanças}

Os micro e os pequenos empreendedores encontram dificuldade ou mesmo falta de acesso ao crédito tradicional oferecido pelo sistema bancário e pelos investidores (Ribeiro \& Carvalho, 2006). Quando conseguem financiamento, geralmente, os juros são elevados, principalmente devido à falta de ativos que possam ser utilizados como garantia nas operações de crédito. Os conceitos de microcrédito e de microfinanças muitas vezes são confundidos, sendo até mesmo considerados idênticos, principalmente por autores estrangeiros como Ledgerwood (1999), Hermes et al. (2008), Haya (2005) e Sterren (2008). Entretanto, há outra vertente que define os termos como distintos, por exemplo: Soares e Melo Sobrinho (2008), Barone (2008), Rodrigues e Pernomo (2011), Martins et al. (2002).

Para Martins et al. (2002), microfinanças é qualquer serviço financeiro ofertado a pessoas de baixa renda, sejam elas empregadas ou trabalhadores informais. De acordo com Ledgewood (1999), as intermediações financeiras realizadas pelas IMFs geralmente estão associadas a produtos de poupança e crédito, mas também podem fornecer serviços ligados a cobrança e a seguros. Além disso, as IMFs atuam não simplesmente como extensão do sistema bancário, mas conjuntamente, como ferramenta de desenvolvimento social, promovendo a integração e a formação de grupos solidários, bem como a capacitação e o ensino gerencial e financeiro para os tomadores. A principal missão das IMFs é aliviar a pobreza e promover o empoderamento feminino especialmente em áreas rurais (Serrano-Cinca \& Gutiérrez-Nieto, 2014). As IMFs devem oferecer serviços adequados e sustentáveis a seus clientes e podem ser constituídas por instituições bancárias stricto sensu (bancos, financeiras, cooperativas de créditos e bancos de desenvolvimento) ou não (ONG e organização da sociedade civil de interesse público (OSCIP)) (Soares \& Melo Sobrinho, 2008). Conforme Dias e Psico (2008), as IMFs devem ser autossuficientes, e seus retornos sem subsídios devem cobrir todos os custos operacionais.

O microcrédito pode ser considerado como a atividade principal dentre as microfinanças (Soares \& Melo Sobrinho, 2008). Desenvolveu-se principalmente na segunda metade do século $X X$ como resposta as falhas dos tradicionais programas de desenvolvimento econômico (Mia \& Chandran, 2015). Consiste em empréstimos de pequeno valor, dado a microempreendedores ou membros da economia informal para potencializar o desenvolvimento de pequenos negócios mediante a concessão de crédito ágil para aqueles que não possuem capacidade ou condição de pleitear investimento ao sistema bancário tradicional (Martins et al., 2002). A função do microcrédito está voltada para a produção, por meio de empréstimos para capital de giro e investimento, concedido com base em metodologia específica (Soares \& Melo Sobrinho, 2008).

Conforme demonstrado por Ledgerwood (1999), as taxas de juros são negociadas a valores inferiores aos cobrados pelas instituições bancárias tradicionais, devendo evitar um trade-off entre o alcance dos mais pobres e a viabilidade financeira; a criação de mecanismos de análises informais na análise, exige a flexibilização dos requerimentos burocráticos; e utilizam-se garantias substitutivas. Kraychete (2005) afirma que os aspectos mais relevantes do microcrédito não necessariamente estão ligados ao valor dos recursos ofertados para cada tomador, e sim ao tipo de destinatário e à tecnologia adotada por ele. Na tentativa de resumir os principais pontos presentes nas definições sobre microcrédito, apresentam-se os seguintes itens, conforme Bello Filho (2010) e Martins et al. (2002)

a) As microfinanças contêm o microcrédito;

b) Pequeno valor das operações;

c) Clientela composta por pessoas de baixa renda, que usualmente não têm acesso a crédito na rede bancária;

d) Empréstimos destinados a atividades produtivas;

e) Empréstimos garantidos por meio do aval solidário

O microcrédito deve vir acompanhado de um caráter incentivador da promoção social dos tomadores. Com isso, a questão das garantias substitutivas torna-se o ponto crucial para o desenvolvimento das políticas de microfinanciamento. A maior parte das pessoas que utilizam este tipo de empréstimo é composta por cidadãos considerados pobres; ou seja, que vivem com menos de quatro dólares por dia (Rodríguez \& Perdomo, 2011). Nesse caso, muito provavelmente, são indivíduos que não possuem bens que possam 
ser utilizados como garantia e também não possuem avalistas. Para tentar solucionar isso, o Grameen Bank de Bangladesh criou o sistema de grupos solidários (Neri, 2008), que funciona com a formação de grupos de tomadores, geralmente ligados por laços de vizinhanças ou consanguíneos, em que todos são responsáveis pelo pagamento de cada membro. Caso um indivíduo não pague, os outros arcam com o "prejuízo". Além disso, os valores dos empréstimos são feitos de forma gradual, em que o histórico positivo de pagamento é um fator essencial para novos e maiores financiamentos. Entretanto, o microcrédito não pode ser considerado uma ferramenta "milagrosa" ou a resposta para todos os problemas relacionados às mazelas sociais. Soares e Melo Sobrinho (2008) afirmam que pessoas com necessidades mais urgentes, como fome e desnutrição, precisam primeiramente de outras formas mais imediatas para resolver seus problemas.

Contudo, não são desprezíveis os resultados alcançados pelos programas de microcrédito em diversas partes do mundo. "A multiplicação de experiências bem sucedidas provou que se pode servir os que até então não tinham acesso aos bancos, começandose a olhar com interesse este nicho de mercado" (Dias \& Psico, 2008 p. 45). Por isso deve-se entender cada vez mais a importância e a penetrabilidade das IMFs na melhoria da qualidade de vida e na geração de renda nas comunidades servidas por esse tipo de programa.

\section{METODOLOGIA}

Esta pesquisa pode ser classificada como descritiva e quantitativa, pois teve como objetivo a descrição de determinada realidade (Gil, 1999). A coleta de dados foi feita por meio de survey. Essa técnica é uma espécie particular de pesquisa social empírica (Babbie, 1999) e é definida como um estudo que visa à obtenção de dados sobre características, ações, opiniões de determinado grupo de pessoas. Normalmente, o instrumento de pesquisa utilizado para obter esses dados é o de questionário (Freitas et al., 2000).

Para a definição da seleção da amostra, levou-se em consideração o nível de confiança de $90 \%$, assim como a margem de erro de $6 \%$. Tendo que a população total de clientes do Crediamigo Capelinha é de aproximadamente 8.500 credores, a amostra ficou composta de 182 respondentes para se alcançar a significância desejada. Nesse caso, os participantes foram selecionados de três formas distintas: i) na agência Crediamigo no município de Capelinha; ii) visita aos clientes acompanhando os agentes de crédito e iii) visita ao local trabalho dos empreendedores.

\section{O método (cluster analysis)}

A análise de agrupamento ou cluster analysis é uma técnica de análise multivariada que engloba uma série de algoritmos, em que se busca reunir os indivíduos em grupos similares, separando-os dos demais (Bussab, Miazaki e Andrade, 1990). Esses agrupamentos devem possuir elevada homogeneidade interna (dentro dos agrupamentos) e heterogeneidade externa (entre agrupamentos). Quando isso ocorre, os objetos do mesmo grupo ficam próximos, e os de grupos diferentes ficam distantes numa representação gráfica (Hair, Anderson \& Tatham, 2005). De forma resumida, a cluster analysis é feita a partir de um conjunto de $n$ indivíduos, e por meio deles encontram-se informações para $k$ grupos ou variáveis. Nesse caso, os indivíduos serão agrupados de modo que fiquem o mais próximo possível do seu grupo e o mais distante dos demais.

Logo, para atender aos objetivos propostos neste estudo, foram selecionadas seis variáveis que dizem respeito a microcrédito e a inclusão bancária. Essas proxys foram utilizadas na formação dos clusters. As variáveis de agrupamento são:

- Valor do financiamento

- Modalidade

- Outro financiamento

- Quantidade de financiamentos

- Quantidade de parcelas

- Instrumentos de orientação

\section{RESULTADOS}

Os clusters foram definidos a partir de seis variáveis, relacionadas ao processo de financiamento. Como as variáveis estão em escalas distintas, foi necessário fazer a padronização, para melhor adequação no modelo.

Em seguida, procedeu-se à escolha da técnica de agrupamento: o modelo Ward, em que são calculadas as distâncias euclidianas quadradas, pelo método hierárquico para a geração dos "esquemas de aglomeração" e a identificação do o número de clusters formados em cada processo. A Figura 2 revela que a maioria das observações está na altura entre 4 e 5 em relação à distância, o que demonstra que a melhor divisão dos agrupamentos será feita com quatro conjuntos de dados. Isso ocorre devido à chamada "regra da parada", em que, quanto menor os coeficientes, mais homogêneos os agrupamentos formados, e, quando um agrupamento torna-se menos homogêneo que a média do anterior, o critério é a parada do processo e a adoção daquele número de clusters (Hair et al., 2005).

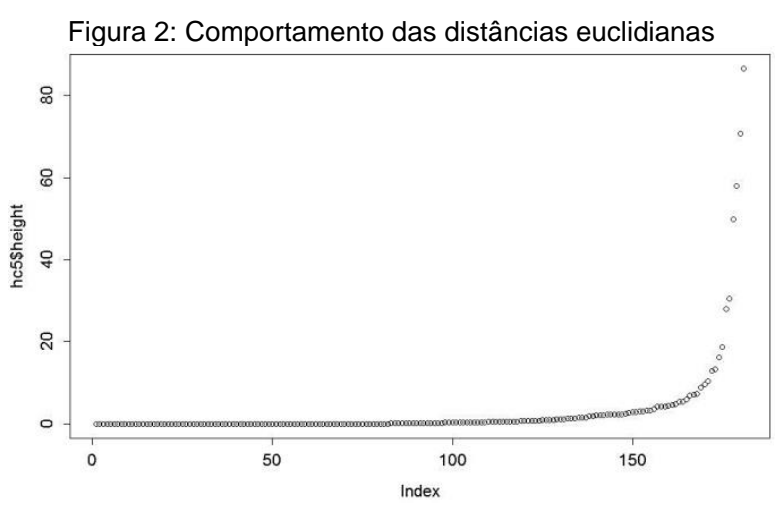

Fonte: Elaborada pelo autor

Uma vez definida a quantidade de conjuntos, elaborou-se o dendograma, bem como a divisão dos agrupamentos. O primeiro grupo foi definido com 81 observações, o segundo, com 25, o terceiro, com 47, e o quarto, com 29 elementos. A Figura 3 mostra a separação nos quatro grandes compostos de dados. 
Figura 3: Dendograma dos clusters formados

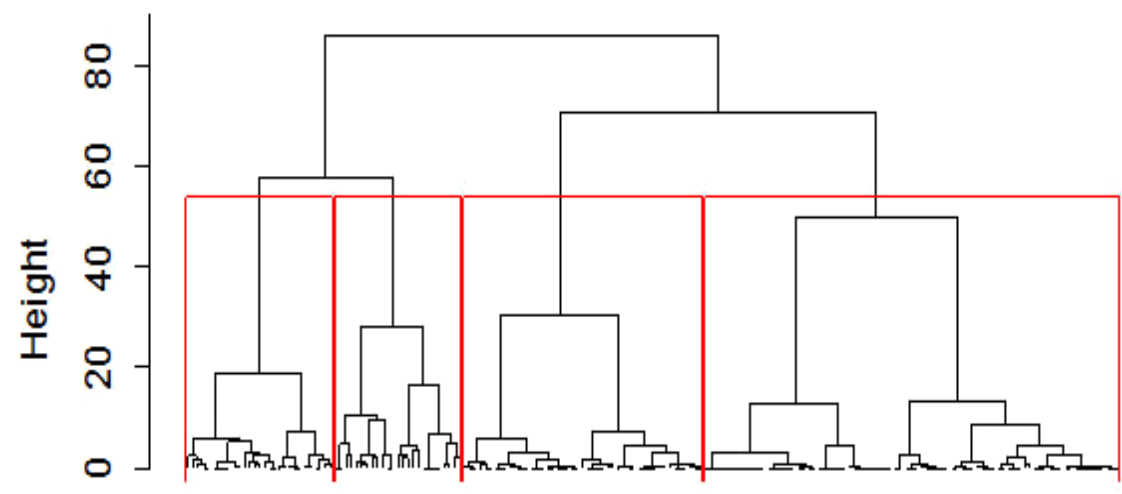

Distância Euclidiana (Ward)

Fonte: Elaborado pelo autor

\section{Resultado da análise}

Para entender os parâmetros utilizados na definição dos clusters, foi necessário realizar a análise descritiva das variáveis de entrada, para esclarecer as principais diferenças entre eles e o perfil médio das observações de cada conglomerado.

Tabela 1: Estatísticas descritivas da variável valor do financiamento

\begin{tabular}{l|r|r|r|r|r|r|r|r}
\hline & N & \multicolumn{1}{c}{ Média } & DesvPad & \multicolumn{1}{c}{ Mínimo } & \multicolumn{1}{c}{ Q1 } & Mediana & \multicolumn{1}{c}{ Q3 } & Máximo \\
\hline Cluster 1 & 81 & 1189,6 & 812,2 & 300 & 500 & 1000 & 1800 & 3000 \\
\hline Cluster 2 & 25 & 4820 & 2148 & 600 & 2750 & 5000 & 6000 & 8000 \\
\hline Cluster 3 & 47 & 1472 & 908 & 300 & 800 & 1300 & 2000 & 4000 \\
\hline Cluster 4 & 29 & 2097 & 1344 & 300 & 1000 & 2000 & 3000 & 6000 \\
\hline
\end{tabular}

Fonte: Elaborada pelo autor

A primeira variável estudada diz respeito ao valor do atual contrato de financiamento. Conforme a Tabela 1, é possível visualizar cada um dos grupos. Em cada cluster é possível observar que as médias e as medianas são de valores muito próximos. Entretanto, é possível notar que os agrupamentos 1 e 3 são compostos por empréstimos de menor valor, enquanto os outros dois são de maior valor em relação tanto às médias quanto ao valor máximo. Contudo, somente o valor não foi algo exclusivo na definição dos conglomerados, uma vez que os valores mínimos de todos os grupos são baixos, entre $\mathrm{R} \$ 300,00$ e $\mathrm{R} \$ 600,00$.

Quadro 2: Modalidade de financiamento

\begin{tabular}{|c|c|c|c|c|c|c|}
\hline & \multicolumn{3}{|c|}{ Cluster 1} & \multicolumn{3}{|c|}{ Cluster 2} \\
\hline \multirow{9}{*}{ Modalidade } & Opção & Frequência & $\%$ & Opção & Frequência & $\%$ \\
\hline & Grupo & 81 & 100 & Grupo & 13 & 52 \\
\hline & Individual & 0 & 0 & Individual & 12 & 48 \\
\hline & Total & 81 & 100 & Total & 25 & 100 \\
\hline & \multicolumn{3}{|c|}{ Cluster 3} & \multicolumn{3}{|c|}{ Cluster 4} \\
\hline & Opção & Frequência & $\%$ & Opção & Frequência & $\%$ \\
\hline & Grupo & 47 & 100 & Grupo & 29 & 100 \\
\hline & Individual & 0 & 0 & Individual & 0 & 0 \\
\hline & Total & 47 & 100 & Total & 29 & 100 \\
\hline
\end{tabular}

Em relação à modalidade de financiamento adquirida no último contrato (Quadro 2), é possível notar a predominância de empréstimos em grupo. Nos clusters 1, 3 e 4, há somente esse tipo, e o individual aparece somente no grupo 2. Uma vez que o segundo conglomerado é composto por desembolsos maiores (Tabela 1), pode-se concluir que os financiamentos pessoais são disponibilizados com valores mais elevados.
Outro item analisado diz respeito ao acesso a financiamento em outras instituições bancárias. Esse item é apresentado no quadro 3, no qual o cluster 4 aparece com indivíduos que possuem financiamentos em outras instituições. No agrupamento 2, existe uma ocorrência de $24 \%$ de outros empréstimos. Já nos conglomerados 1 e 3 , o Crediamigo corresponde à única forma de crédito para os indivíduos participantes. 
Quadro 3: Contratação de outros financiamentos em instituições bancárias distintas

\begin{tabular}{|c|c|c|c|c|c|c|}
\hline \multirow{10}{*}{$\begin{array}{c}\text { Outro } \\
\text { financiamento }\end{array}$} & \multicolumn{3}{|c|}{ Cluster 1} & \multicolumn{3}{|c|}{ Cluster 2} \\
\hline & Opção & Frequência & $\%$ & Opção & Frequência & $\%$ \\
\hline & Não & 81 & 100 & Não & 19 & 76 \\
\hline & Sim & 0 & 0 & Sim & 6 & 24 \\
\hline & Total & 81 & 100 & Total & 25 & 100 \\
\hline & \multicolumn{3}{|c|}{ Cluster 3} & \multicolumn{3}{|c|}{ Cluster 4} \\
\hline & Opção & Frequência & $\%$ & Opção & Frequência & $\%$ \\
\hline & Não & 47 & 100 & Não & 0 & 0 \\
\hline & Sim & 0 & 0 & Sim & 29 & 100 \\
\hline & Total & 47 & 100 & Total & 29 & 100 \\
\hline
\end{tabular}

Fonte: Elaborado pelo autor

Em relação ao número de financiamentos firmados com o Crediamigo, pode-se notar pelo do Quadro 4 que, em todos os clusters, há uma predominância de usuários que fizeram cinco ou mais empréstimos. No caso do conglomerado 2 , onde há uma presença maior de contratos individuais e desembolso em valores mais elevados, é possível supor que há um aumento gradativo do capital emprestado ao longo do tempo. É importante notar o elevado percentual, variando entre $17 \%$ e $36 \%$, dependendo do agrupamento de usuários que estão na segunda ou terceira operação.

Quadro 4: Número de vezes que recorreram ao financiamento do Crediamigo

\begin{tabular}{|c|c|c|c|c|c|c|}
\hline \multirow{14}{*}{ Quantidade de financiamentos } & \multicolumn{3}{|c|}{ Cluster 1} & \multicolumn{3}{|c|}{ Cluster 2} \\
\hline & Opção & Frequência & $\%$ & Opção & Frequência & $\%$ \\
\hline & $1 \mathrm{vez}$ & 11 & 13,58 & $1 \mathrm{vez}$ & 1 & 4,0 \\
\hline & 2 ou 3 vezes & 23 & 28,4 & 2 ou 3 vezes & 6 & 24,0 \\
\hline & 4 ou 5 vezes & 10 & 12,35 & 4 ou 5 vezes & 1 & 4,0 \\
\hline & $>5$ vezes & 37 & 45,68 & $>5$ vezes & 17 & 68,0 \\
\hline & Total & 81 & 100 & Total & 25 & 100 \\
\hline & \multicolumn{3}{|c|}{ Cluster 3} & \multicolumn{3}{|c|}{ Cluster 4} \\
\hline & Opção & Frequência & $\%$ & Opção & Frequência & $\%$ \\
\hline & $1 \mathrm{vez}$ & 6 & 12,77 & $1 \mathrm{vez}$ & 2 & 6,9 \\
\hline & 2 ou 3 vezes & 17 & 36,17 & 2 ou 3 vezes & 5 & 17,24 \\
\hline & 4 ou 5 vezes & 5 & 10,64 & 4 ou 5 vezes & 8 & 27,59 \\
\hline & $>5$ vezes & 19 & 40,43 & $>5$ vezes & 14 & 48,28 \\
\hline & Total & 47 & 100 & Total & 29 & 100 \\
\hline
\end{tabular}

Fonte: Elaborado pelo autor

Nos programas de microcrédito, os contratos costumam ser de curta duração e com pagamentos regulares com intervalos pequenos entre uma parcela e outra. Por isso, é importante analisar o do tamanho do tratado de financiamento. Os clusters 1, 3 e 4 são compostos somente por empréstimos adquiridos por Grupo Solidário, diferenciando do agrupamento 2 , de quem possui os dois tipos. O número de parcelas em cada conglomerado pode ser observado no Quadro 5. Entretanto, é importante ressaltar que na observação direta, realizada na agência Capelinha do Crediamigo, e nas entrevistas semiestruturadas foi notada a existência de contratos de seis meses para financiamentos em grupo e de treze meses para empréstimos individuais. Logo, é possível ter ocorrido erro por parte dos respondentes que marcaram as opções de 2, 5, 8 e 12 parcelas.

Quadro 5: Quantidade de parcelas do último contrato de financiamento

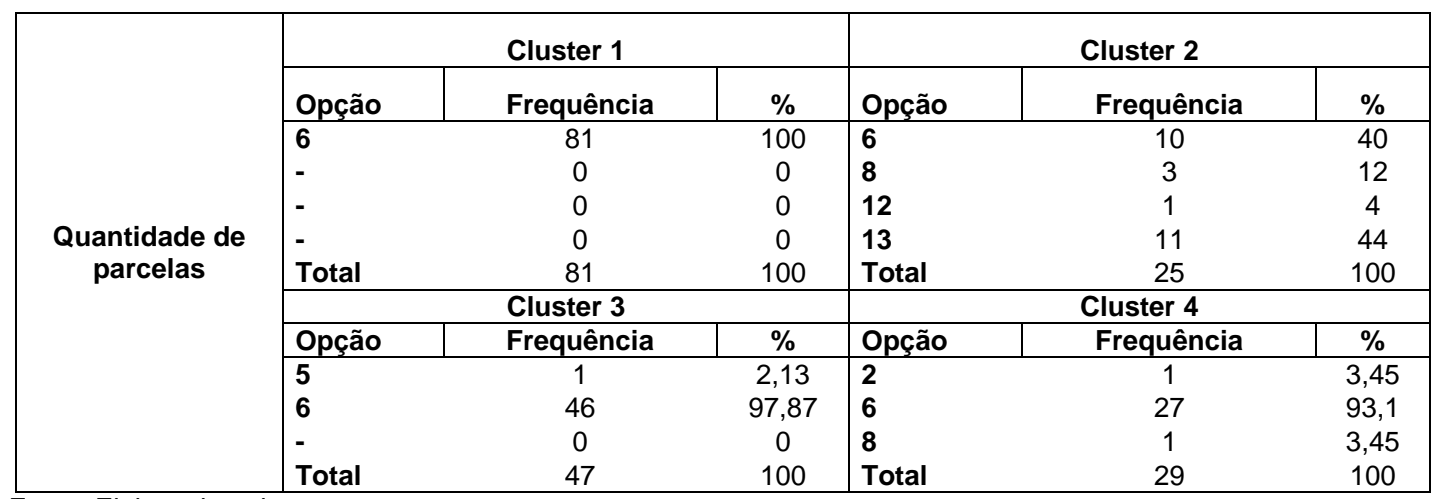

Fonte: Elaborado pelo autor

Outro assunto importante no que tange ao microcrédito é a orientação da IMF aos microempreendedores. O quadro mostra que essa variável foi importante na diferenciação dos clusters 1 e 3 , sendo que nesses agrupamentos o comportamento das outras 
variáveis é semelhante. Contudo, nesse caso o conglomerado 1 é composto $100 \%$ por clientes que afirmaram que receberam orientação ou acompanhamento dos seus negócios. De outro lado, a totalidade do grupo 3 é de usuários que afirmaram que não receberem nenhum auxílio. Já nos clusters 2 e 4 existem as duas situações.

Quadro 6: Instrumentos de orientação ao microempreendedor

\begin{tabular}{|c|l|c|c|l|c|c|}
\hline & \multicolumn{3}{|c|}{ Cluster 1 } & \multicolumn{3}{c|}{ Cluster 2 } \\
\cline { 2 - 7 } & Opção & Frequência & $\%$ & Opção & Frequência & $\%$ \\
\cline { 2 - 7 } & Não & 0 & 0 & Não & 14 & 56 \\
\multirow{4}{*}{$\begin{array}{c}\text { Instrumentos de } \\
\text { orientação }\end{array}$} & Sim & 81 & 100 & Sim & 11 & 44 \\
\cline { 2 - 7 } & Total & 81 & 100 & Total & 25 & 100 \\
\cline { 2 - 7 } & \multicolumn{7}{|c|}{ Cluster 3 } & Frequência & $\%$ & Opção & Frequência & $\%$ \\
\cline { 2 - 7 } & Opão & 47 & 100 & Não & 11 & 37,93 \\
& São & 0 & 0 & Sim & 18 & 62,07 \\
& Sim & 47 & 100 & Total & 29 & 100 \\
\hline
\end{tabular}

Fonte: Elaborado pelo autor

\section{Caracterização dos negócios apoiados pelo microcrédito}

A etapa seguinte corresponde ao perfil dos negócios apoiados pelo programa Crediamigo em Capelinha e região. Foram analisados: grau de formalização, quantidade de funcionários, faturamento e lucratividade, local de funcionamento, tempo de empreendimento, maneira como investem o lucro, se possuem controle financeiro do negócio e se corresponde à atividade principal.

Quadro 7: Se o negócio é a atividade principal

\begin{tabular}{|c|c|c|c|c|c|}
\hline \multicolumn{3}{|c|}{ Cluster 1} & \multicolumn{3}{|c|}{ Cluster 2} \\
\hline Opção & Frequência & $\%$ & Opção & Frequência & $\%$ \\
\hline Não & 32 & 39,5 & Não & 3 & 12,0 \\
\hline Sim & 49 & 60,5 & Sim & 22 & 88,0 \\
\hline Total & 81 & 100,0 & Total & 25 & 100,0 \\
\hline \multicolumn{3}{|c|}{ Cluster 3} & \multicolumn{3}{|c|}{ Cluster 4} \\
\hline Opção & Frequência & $\%$ & Opção & Frequência & $\%$ \\
\hline Não & 23 & 48,9 & Não & 12 & 41,4 \\
\hline Sim & 24 & 51,1 & Sim & 17 & 58,6 \\
\hline Total & 47 & 100,0 & Total & 29 & 100,0 \\
\hline
\end{tabular}

A Tabela corresponde à questão sobre as motivações para se iniciar o negócio. Como, muitas, vezes os objetivos são múltiplos, foi permitida a marcação de mais de uma alternativa. A opção majoritária nos clusters 1 , 3 e 4 corresponde à "complementação de renda". Isso é explicado, pois nesses agrupamentos há um elevado percentual de empreendedores que têm a atividade em tela como sendo complementar. Já no conglomerado 2 , em que $88 \%$ têm a
A atividade apoiada pelo Crediamigo, apontada nos clusters 1, 3, 4, é a fonte principal de rendimentos entre $50 \%$ e $61 \%$, conforme o quadro 7 . Porém, no agrupamento 2 , aproximadamente $90 \%$ dos indivíduos citaram essa opção. É imperioso notar que é no referido grupo se encontram os melhores indicadores em relação à escolaridade, ao valor de financiamento e à classe social.

Tabela 2: Motivação para abertura do negócio

\begin{tabular}{c|c|c|c|c|c|c|c}
\hline Cluster & $\begin{array}{c}\text { Falta de } \\
\text { Emprego } \\
\text { Formal } \\
(\%)\end{array}$ & $\begin{array}{c}\text { Oportunidade } \\
\text { de Negócios } \\
(\%)\end{array}$ & $\begin{array}{c}\text { Complementar a } \\
\text { renda (\%) }\end{array}$ & $\begin{array}{c}\text { Indicação de } \\
\text { amigos ou } \\
\text { familiares } \\
(\%)\end{array}$ & $\begin{array}{c}\text { Uso de } \\
\text { indenização } \\
\text { por demissão } \\
\text { (FGTS, seguro } \\
\text { desemprego e } \\
\text { etc..) (\%) }\end{array}$ & $\begin{array}{c}\text { Ocupação após } \\
\text { a aposentadoria } \\
(\%)\end{array}$ & $\begin{array}{c}\text { Outro } \\
(\%)\end{array}$ \\
\hline $\mathbf{1}$ & 42 & 52 & 89 & 10 & 0 & 0 & 0 \\
\hline $\mathbf{2}$ & 44 & 40 & 40 & 16 & 8 & 0 & 0 \\
\hline $\mathbf{3}$ & 40 & 47 & 60 & 13 & 0 & 0 & 4 \\
\hline $\mathbf{4}$ & 45 & 52 & 76 & 17 & 0 & 3 & 3 \\
\hline
\end{tabular}

Fonte: Elaborada pelo autor.

Apenas $37 \%$ da população do Vale do Jequitinhonha é formada por trabalhadores formalizados (Programa das Nações Unidas para atividade como principal fonte de renda, há um equilíbrio entre as opções sobre falta de emprego formal, oportunidade de negócios e complementação de renda. Contudo, não é possível distinguir claramente se o empreendedorismo na região ocorre mais por oportunidade ou por necessidade, uma vez que em todos os grupos há um equilíbrio nessas alternativas. 
Por meio da Lei Complementar 128, de 19 de dezembro de 2008, o Governo Federal regulamentou a figura do microempreendedor individual (MEI). Entretanto, a nova figura jurídica é pouco representada em todos os clusters. Novamente, os agrupamentos 1, 3, 4 revelam comportamento parecido, com elevado nível de informalidade. $E$ no conglomerado 2, em que estão as microempresas mais estruturadas e com maior faturamento, é que se encontra o nível bem mais elevado de negócios formais (48\%). Isso, juntamente com os participantes do MEI, torna o cluster o único com mais de $50 \%$ dos microempreendimentos devidamente regulamentados.

Quadro 8: Grau de formalização

\begin{tabular}{|c|c|c|c|c|c|}
\hline \multicolumn{3}{|c|}{ Cluster 1} & \multicolumn{3}{|c|}{ Cluster 2} \\
\hline Opção & Frequência & $\%$ & Opção & Frequência & $\%$ \\
\hline Formal & 3 & 3,7 & Formal & 12 & 48,0 \\
\hline Informal & 66 & 81,5 & Informal & 10 & 40,0 \\
\hline MEI & 7 & 8,6 & MEI & 2 & 8,0 \\
\hline Em formalização & 5 & 6,2 & Em formalização & 1 & 4,0 \\
\hline Total & 81 & 100,0 & Total & 25 & 100,0 \\
\hline \multicolumn{3}{|c|}{ Cluster 3} & \multicolumn{3}{|c|}{ Cluster 4} \\
\hline Opção & Frequência & $\%$ & Opção & Frequência & $\%$ \\
\hline Formal & 6 & 12,8 & Formal & 2 & 6,9 \\
\hline Informal & 32 & 68,1 & Informal & 23 & 79,3 \\
\hline MEI & 8 & 17,0 & MEI & 3 & 10,3 \\
\hline Em formalização & 1 & 2,1 & Em formalização & 1 & 3,5 \\
\hline Total & 47 & 100,0 & Total & 29 & 100,0 \\
\hline
\end{tabular}

O quadro apresenta a quantidade de pessoas que trabalham nos empreendimentos. Outra vez, o cluster 2 se destaca tendo $76 \%$ dos negócios como geradores de empregos, fato que também pode ser explicado pela melhor estruturação do negócio, pelo maior nível de escolaridade dos proprietários e pelo maior faturamento médio. O agrupamento 4 também mostra uma maioria (52\%), em que trabalham mais de uma pessoa. Já os conglomerados 1 e 3 são compostos majoritariamente por trabalhadores individuais.

Quadro 9: Quantidade de pessoas que trabalham no empreendimento

\begin{tabular}{|c|c|c|c|c|c|}
\hline \multicolumn{3}{|c|}{ Cluster 1} & \multicolumn{3}{|c|}{ Cluster 2} \\
\hline Opção & Frequência & $\%$ & Opção & Frequência & $\%$ \\
\hline Apenas 1 & 46 & 56,8 & Apenas 1 & 6 & 24 \\
\hline Duas pessoas & 29 & 35,8 & Duas pessoas & 8 & 32 \\
\hline Três pessoas & 5 & 6,2 & Três pessoas & 2 & 8 \\
\hline Entre 4 e 10 & 1 & 1,2 & Entre 4 e 10 & 8 & 32 \\
\hline Entre 11 e 20 & 0 & 0 & Entre 11 e 20 & 1 & 4 \\
\hline Mais de 20 & 0 & 0 & Mais de 20 & 0 & 0 \\
\hline Total & 81 & 100 & Total & 25 & 100 \\
\hline \multicolumn{3}{|c|}{ Cluster 3} & \multicolumn{3}{|c|}{ Cluster 4} \\
\hline Opção & Frequência & $\%$ & Opção & Frequência & $\%$ \\
\hline Apenas 1 & 30 & 63,8 & Apenas 1 & 14 & 48,3 \\
\hline Duas pessoas & 11 & 23,4 & Duas pessoas & 8 & 27,6 \\
\hline Três pessoas & 3 & 6,4 & Três pessoas & 2 & 6,9 \\
\hline Entre 4 e 10 & 1 & 2,1 & Entre 4 e 10 & 5 & 17,2 \\
\hline Entre 11 e 20 & 1 & 2,1 & Entre 11 e 20 & 0 & 0 \\
\hline Mais de 20 & 1 & 2,1 & Mais de 20 & 0 & 0 \\
\hline Total & 47 & 100 & Total & 29 & 100 \\
\hline
\end{tabular}

O local de funcionamento dos negócios pode ser verificado no Quadro 10. Em todos os clusters, a opção majoritária é de micronegócios que funcionam nas residências dos empreendedores. Observou-se durante a realização da pesquisa 
que uma parcela significativa dos usuários é composta por revendedores de cosméticos, manicures e produtores rurais, que têm como local de trabalho suas próprias moradias. Já a existência de ponto comercial é mais notada no grupo 2 , em que $32 \%$ dos respondentes afirmaram que o possuem.

Quadro 10: Local de Funcionamento

\begin{tabular}{|c|c|c|c|c|c|}
\hline \multicolumn{3}{|c|}{ Cluster 1} & \multicolumn{3}{|c|}{ Cluster 2} \\
\hline Opção & Frequência & $\%$ & Opção & Frequência & $\%$ \\
\hline Residência & 50 & 61,7 & Residência & 10 & 40,0 \\
\hline Ponto Comercial & 13 & 16,1 & Ponto Comercial & 8 & 32,0 \\
\hline Serviço a domicílio & 15 & 18,5 & Serviço a domicílio & 3 & 12,0 \\
\hline Ambulante & 3 & 3,7 & Ambulante & 2 & 8,0 \\
\hline Outro & 0 & 0,0 & Outro & 2 & 8,0 \\
\hline Total & 81 & 100,0 & Total & 25 & 100,0 \\
\hline \multicolumn{3}{|c|}{ Cluster 3} & \multicolumn{3}{|c|}{ Cluster 4} \\
\hline Opção & Frequência & $\%$ & Opção & Frequência & $\%$ \\
\hline Residência & 17 & 36,2 & Residência & 13 & 44,8 \\
\hline Ponto Comercial & 9 & 19,2 & Ponto Comercial & 7 & 24,1 \\
\hline Serviço a domicílio & 12 & 25,5 & Serviço a domicílio & 6 & 20,7 \\
\hline Ambulante & 6 & 12,8 & Ambulante & 2 & 6,9 \\
\hline Outro & 3 & 6,4 & Outro & 1 & 3,5 \\
\hline Total & 47 & 100,0 & Total & 29 & 100,0 \\
\hline
\end{tabular}

Em todos os grupos, há uma taxa média de $50 \%$ para empresas com mais de cinco anos de existência (quadro). Isso pode ser usado como argumentação para a eficiência do Crediamigo, como forma de apoio às empresas. Entretanto, $27 \%$ das empresas no Brasil fecham no primeiro ano. Daquelas que sobrevivem ao período de dois anos, $73 \%$ tendem a chegar a cinco anos ou mais (Serviço Brasileiro de Apoio às Micro e Pequenas Empresas [SEBRAE], 2011). Logo, não é possível afirmar por si só a influência da IMF na sustentação dos microempreendimentos somente com os dados em tela.

Quadro 11: Tempo de existência do negócio

\begin{tabular}{|l|c|c|l|c|c|}
\hline \multicolumn{3}{|c|}{ Cluster 1 } & \multicolumn{3}{c|}{ Cluster 2 } \\
\hline Opção & Frequência & $\%$ & Opção & Frequência & $\%$ \\
\hline Menos de 1 ano & 18 & 22,2 & Menos de 1 ano & 1 & 4,0 \\
Entre 1 e 3 anos & 16 & 19,8 & Entre 1 e 3 anos & 10 & 40,0 \\
Entre 3 e 5 anos & 3 & 3,7 & Entre 3 e 5 anos & 2 & 8,0 \\
Mais de 5 anos & 44 & 54,3 & Mais de 5 anos & 12 & 48,0 \\
Total & 81 & 100,0 & Total & 25 & 100,0 \\
\hline \multicolumn{7}{c}{ Cluster 3 } & & & Cluster 4 & Frequência & $\%$ \\
\hline Opção & Frequência & $\%$ & Opção & 2 & 6,9 \\
\hline Menos de 1 ano & 1 & 2,1 & Menos de 1 ano & 5 & 17,2 \\
Entre 1 e 3 anos & 14 & 29,8 & Entre 1 e 3 anos & 6 & 20,7 \\
Entre 3 e 5 anos & 6 & 12,8 & Entre 3 e 5 anos & 16 & 55,2 \\
Mais de 5 anos & 26 & 55,3 & Mais de 5 anos & 29 & 100,0 \\
\hline
\end{tabular}

Em relação à lucratividade, ou seja, ao percentual de lucro sobre faturamento, é possível observar um comportamento semelhante entre os clusters. A média e a mediana estão na faixa de $50 \%$, o que pode ser considerado como normal. Entretanto, foram encontrados respondentes que marcaram a opção de 100\% de lucratividade, o que pode ser considerado um equívoco, já que todas as atividades possuem alguns custos, mesmo que não contabilizados. 
Tabela 3: Faturamento, lucro e lucratividade

\begin{tabular}{|c|c|c|c|c|c|c|c|}
\hline \multicolumn{8}{|c|}{ Cluster 1} \\
\hline Variável & Média & DesvPad & Mínimo & Q1 & Mediana & Q3 & Máximo \\
\hline Faturamento $(\mathbf{R} \$)$ & 1.831 & 1.919 & 100 & 500 & 1.100 & 2.500 & 9.000 \\
\hline Lucro (R\$) & 821,6 & 788,1 & 50 & 200 & 600 & 1.200 & 3.400 \\
\hline Lucro/Faturamento & 0,4811 & 0,175 & 0 & 0,375 & 0,4688 & 0,5774 & 1 \\
\hline \multicolumn{8}{|c|}{ Cluster 2} \\
\hline Variável & Média & DesvPad & Mínimo & Q1 & Mediana & Q3 & Máximo \\
\hline Faturamento $(\mathbf{R} \$)$ & 7.104 & 7.961 & 200 & 1.300 & 4.900 & 10.050 & 30.000 \\
\hline Lucro (R\$) & 3.816 & 5.312 & 150 & 500 & 2.400 & 4.500 & 20.000 \\
\hline Lucro/Faturamento & 0,5125 & 0,1857 & 0,2083 & 0,3875 & 0,4898 & 0,6667 & 0,8571 \\
\hline \multicolumn{8}{|c|}{ Cluster 3} \\
\hline Variável & Média & DesvPad & Mínimo & Q1 & Mediana & Q3 & Máximo \\
\hline Faturamento (R\$) & 2.498 & 2.680 & 100 & 720 & 1.600 & 3.000 & 13.500 \\
\hline Lucro (R\$) & 1.268 & 1.239 & 100 & 400 & 750 & 2.000 & 5.500 \\
\hline Lucro/Faturamento & 0,5685 & 0,227 & 0,2143 & 0,3636 & 0,5 & 0,75 & 1 \\
\hline \multicolumn{8}{|c|}{ Cluster 4} \\
\hline Variável & Média & DesvPad & Mínimo & Q1 & Mediana & Q3 & Máximo \\
\hline Faturamento ( $\mathbf{R} \$)$ & 3.988 & 5.219 & 100 & 800 & 2.000 & 4.700 & 20.000 \\
\hline Lucro (R\$) & 1.629 & 1.847 & 80 & 350 & 800 & 2.200 & 7.000 \\
\hline Lucro/Faturamento & 0,4902 & 0,1909 & 0,1 & 0,4 & 0,4688 & 0,5817 & 1 \\
\hline
\end{tabular}

A questão sobre a aplicação dos valores levantados nos financiamentos possibilitou aos respondentes a escolha de mais de uma opção, uma vez que o uso não se limita a uma só alternativa. O resultado pode ser visto na Tabela. Em todos os grupos, a variável relativa à compra de mercadorias e insumos teve maioria. Entretanto, no cluster 2 ela não foi absoluta. Nesse mesmo conglomerado, é possível notar maior equilíbrio nas respostas. Porém é importante ressaltar pelas análises anteriores que nesse segmento encontram-se os negócios financeiramente mais desenvolvidos e a maior escolaridade média dos empreendedores.
No conglomerado 1, é possível notar um percentual de quase $50 \%$ que afirmaram utilizar os empréstimos para comprar bens de consumo, o que está em desacordo com os objetivos do Crediamigo, que é para utilização somente para aplicação produtiva. Além disso, em todos os clusters há uma presença superior a $20 \%$ para a compra de bens de consumo. Isso demonstra que, a despeito dos critérios adotados pela IMF na seleção dos clientes, ainda não é possível controlar que o capital seja totalmente investido na produção ou comercialização dos produtos e serviços.

Tabela 4: Uso do empréstimo

\begin{tabular}{|c|c|c|c|c|c|c|c|c|}
\hline Cluster & $\begin{array}{l}\text { Capital } \\
\text { de giro } \\
(\%)\end{array}$ & $\begin{array}{c}\text { Mercadoria } \\
\text { e insumos } \\
(\%)\end{array}$ & $\begin{array}{l}\text { Máquinas, } \\
\text { equipamentos } \\
\text { e veículos (\%) }\end{array}$ & $\begin{array}{c}\text { Pagamento } \\
\text { de dívidas } \\
(\%)\end{array}$ & $\begin{array}{c}\begin{array}{c}\text { Pagamento } \\
\text { de } \\
\text { impostos } \\
(\%)\end{array} \\
\end{array}$ & $\begin{array}{c}\text { Contratação } \\
\text { de } \\
\text { funcionários } \\
(\%)\end{array}$ & $\begin{array}{c}\text { Melhoria } \\
\text { no ponto } \\
\text { de venda } \\
(\%)\end{array}$ & $\begin{array}{c}\text { Compra de } \\
\text { bens de } \\
\text { consumo } \\
(\%)\end{array}$ \\
\hline 1 & 10 & 64 & 11 & 35 & 17 & 1 & 11 & 49 \\
\hline 2 & 36 & 36 & 28 & 24 & 8 & 4 & 20 & 24 \\
\hline 3 & 15 & 66 & 26 & 15 & 2 & 2 & 9 & 23 \\
\hline 4 & 10 & 83 & 10 & 31 & 14 & 0 & 17 & 31 \\
\hline $\begin{array}{c}\text { Média } \\
\text { Ponderada }\end{array}$ & 15 & 64 & 17 & 27 & 12 & 2 & 13 & 36 \\
\hline
\end{tabular}

Fonte: Elaborada pelo autor

Em relação ao valor apurado com as vendas e o lucro obtido, em todos os clusters a média ficou próxima de 4 . Isso demonstra que os empreendedores perceberam uma melhora nesses itens. Porém, em relação aos custos, os grupos 1, 3 e 4 definiram que não

Tabela 5: Avaliação impactos do financiamento

\begin{tabular}{c|c|c|c|c|c|c|c|c|c}
\hline Cluster & Vendas & Lucro & Custos & Estoques & $\begin{array}{c}\text { Novos } \\
\text { produtos }\end{array}$ & $\begin{array}{c}\text { Compra de } \\
\text { equipamentos } \\
\text { ferramentas }\end{array}$ & $\begin{array}{c}\text { Contratação } \\
\text { de } \\
\text { funcionários }\end{array}$ & $\begin{array}{c}\text { Investimento } \\
\text { em } \\
\text { propaganda }\end{array}$ & $\begin{array}{c}\text { Compra de } \\
\text { veículos }\end{array}$ \\
\hline $\mathbf{1}$ & 4,16 & 4,19 & 2,98 & 3,98 & 4,00 & 3,68 & 3,00 & 3,12 & 3,47 \\
\hline $\mathbf{2}$ & 3,96 & 3,84 & 2,04 & 3,80 & 3,88 & 3,60 & 3,48 & 3,48 & 3,76 \\
\hline $\mathbf{3}$ & 3,90 & 3,94 & 2,96 & 3,87 & 3,87 & 3,64 & 3,19 & 3,36 & 3,66 \\
\hline $\mathbf{4}$ & 4,17 & 4,07 & 3,03 & 3,90 & 3,97 & 3,69 & 3,31 & 3,24 & 3,52 \\
\hline
\end{tabular}

Fonte: Elaborada pelo autor.

No quesito estoques, em nenhum dos grupos a média foi inferior a 3,80. Isso indica que nessa variável houve uma melhora houve alteração nesse quesito. Já o segundo agrupamento percebeu uma piora, uma vez que, após a aquisição dos empréstimos, os custos aumentaram. percebida em todos os grupos. O mesmo ocorreu com a capacidade de oferecer novos produtos ou serviços. Uma vez que os 
empreendedores possuem um capital maior para investir, eles conseguem diversificar mais o que disponibilizam para seus clientes.

Outras variáveis importantes correspondem a fatores relacionados diretamente a produtividade, divulgação e logística. A compra de máquinas, equipamentos e ferramentas obteve um escore semelhante em todos os clusters, por volta de 3,65, o que demonstra uma percepção positiva, mas não absoluta, de que após a aquisição do microcrédito houve melhora nesse quesito.

A maioria dos empreendimentos corresponde, a atividades individuais ou familiares, com área de atuação local. Por isso, não foi surpresa encontrar os resultados em relação à contratação de funcionários e ao investimento em propaganda. Um número majoritário de empreendedores não investia em propaganda e não tinha funcionários no período anterior à contratação do microcrédito. Essa situação se manteve após o financiamento. Os escores nas duas variáveis mantiveram próximo de 3 , pois não houve alteração percebida.

Finalmente, a compra de veículos para utilização profissional foi avaliada. Em média, os escores ficaram acima de 3,5 pontos, uma vez que uma grande quantidade de empreendedores conseguiu adquirir um automóvel, caminhonete e, principalmente, motocicletas. Esse fato foi notado na observação direta, em especial nos prestadores de serviço e revendedores de produtos cosméticos, que, após a contratação do financiamento, compraram motocicletas para poderem entregar seus produtos ou executar seus serviços.

\section{CONCLUSÃO}

O objetivo principal desta pesquisa foi apurar como o microcrédito pode influenciar o desenvolvimento dos microempreendimentos no Vale do Jequitinhonha. O universo da amostra foi selecionado entre os usuários do programa Crediamigo no entorno do município de Capelinha. A escolha da IMF se fez devido à reconhecida capacidade e eficiência do Banco do Nordeste em fornecer financiamentos para camadas menos favorecidas economicamente da população. A filial apontada foi motivada pela penetrabilidade da instituição financeira na cidade e pelo entorno e os indicadores de eficiência operacional, que aparecem em destaque em comparação com outras unidades.

Na avaliação dos negócios apoiados com o microcrédito, pôdese perceber que se constituem na atividade econômica principal. Entretanto, há uma parcela significativa em todos os clusters de clientes que possuem outras ocupações. Em três grupos houve o predomínio de negócios informais, à exceção no segundo aglomerado, no qual predominam empreendimentos legalizados ou microempreendedores individuais.

Em relação à criação de empregos, há o predomínio de empreendimentos em que não existem funcionários. Novamente, a exceção ocorre no grupo 2 , onde $75 \%$ dos entrevistados possuem um ou mais empregados. Isso também pode ser explicado, pois a grande maioria dos empreendedores está situada nos setores de comércio e serviços, com seus empreendimentos funcionando na residência ou na forma de atendimento a domicílio.
Devido à grande informalidade e à baixa escolaridade, não é surpresa que em todos os grupos os empreendedores não possuam um controle financeiro capaz de discriminar as receitas e as despesas provenientes dos negócios. Entretanto, em relação ao faturamento e ao lucro, foi encontrada uma grande heterogeneidade entre os grupos. Como esperado, é no conglomerado 2 que esses indicadores apresentam maiores valores médios.

Normalmente o capital do financiamento é utilizado para atividade produtiva; por exemplo, compra de mercadorias, insumos, máquinas e equipamentos, bem como para a constituição do capital de giro, significando opções bastante significativas. Porém, mesmo com todo o cuidado na avaliação do crédito feita pelos agentes do Crediamigo, foi encontrado em todos os grupos um percentual que varia entre $23 \%$ e $49 \%$ de usuários que afirmaram ter utilizado parte ou a totalidade do financiamento para a aquisição de bens pessoais.

Os empreendedores perceberam uma mudança positiva no faturamento e no lucro de seus negócios após a aquisição do microcrédito, assim como na compra de estoques e de novos produtos. Porém, quanto à contratação de funcionários e à realização de investimentos em propagandas não perceberam alteração. Contudo, nos custos foi detectada uma piora. Isso pode ter acontecido por pressões inflacionárias ou, mesmo, pelo pagamento das parcelas do financiamento.

Como limitação deste estudo destaca-se a escolha da região do Vale do Jequitinhonha. Não é possível afirmar se os resultados encontrados na área selecionada podem ser considerados em diferentes contextos regionais. Também a própria metodologia de análise de cluster é um limitador, uma vez mesmo sendo uma ferramenta que possibilita uma enorme gama de aplicações em diferentes campos do conhecimento, a cluster analysis exige bastante do julgamento do pesquisador, sendo considerada por muitos como um instrumento de caráter subjetivo (Hair et al. 2005).

Contudo, conclui-se que microcrédito influencia os empreendimentos no Vale do Jequitinhonha, principalmente em relação à manutenção dos fluxos de caixa dos pequenos negócios. Esses empreendedores, outrora excluídos do mercado de crédito tradicional, muitas vezes não conseguiam montar estoques ou comprar insumos por não possuírem capital necessário para tais investimentos. Posteriormente, com a chegada do Crediamigo na região, eles puderem aplicar o capital na compra de produtos à vista, com desconto que, muitas vezes, são maiores que os juros pagos no microfinanciamento. Com isso, tornaram-se mais competitivos e autossustentáveis, sem a necessidade de se ocuparem com outras atividades. Em alguns casos especiais, tornaram-se empresários de sucesso e reconhecidos na região.

A verificação dos resultados obtidos nesta pesquisa pode contribuir para melhorar a aplicação e o acompanhamento dos empreendimentos assistidos com o microcrédito. Por ser uma pesquisa independente e sem relação com o Crediamigo, foi possível que as respostas fossem mais sinceras em relação aos levantamentos feitos pela IMF. Com isso, verificaram-se alguns casos de clientes que estão fora do perfil do público-alvo e mesmo alguns que não utilizam os empréstimos para atividades produtivas. 
Relacionam-se, a seguir, algumas sugestões para estudos futuros sobre o tema em tela:

- Acompanhamento dos empreendimentos em múltiplos períodos de tempo com base em estudos com dados em painéis;

- Avaliação detalhada dos fluxos de caixa e demonstrativos contábeis dos empreendimentos;

- Acompanhamento de negócios que adquirem o primeiro financiamento e impactos imediatos;

- Estudo com uma amostra maior de participantes, com melhor significância estatística e em várias regiões do Vale do Jequitinhonha e Minas Gerais.

Em razão dos impactos positivos apresentados tanto pelos resultados deste estudo quanto por aqueles encontrados na literatura, o microcrédito é um importante campo de estudo para os próximos anos. A compreensão detalhada dos programas de financiamento tidos como referência poder ser usada como benchmarking para a implementação de iniciativas semelhantes em outras localidades do Brasil ou do mundo.

\section{REFERÊNCIAS}

Babbie, E. (1999). Métodos de pesquisas de survey. Ed. da UFMG.

Banco do Nordeste do Brasil. (2013). Programas de Microfinanças do Banco do Nordeste: Relatório 2013. Fortaleza.

Banco do Nordeste do Brasil (2014). Conheça o Crediamigo. Recuperado em 24 de nttp://www.bnb.gov.br/content/aplicacao/Produtos e Servicos/Crediami go/gerados/O_que_e_objetivos.asp

Barone, F. M. (2008). Pesquisa sobre as microfinanças no Brasil. Rio de Janeiro.

Bello Filho, W. de B. (2010). Gênese e Reprodução da Crença na Efiácia da Política de Microcrédito no Combate à pobreza. Universidade Federal do Maranhão.

Bester, H. (1985). Screening vs. rationing in credit markets with imperfect information. The American Economic Review, 75(4), 850-855.

Bussab, W. de O., Miazaki, É. S., \& Andrade, D. F. de. (1990). Introdução à análise de agrupamentos. In $9^{\circ}$ Simpósio Nacional de Probabilidade e Estatística (p. 90). São Paulo: Associação Brasileira de Estatística.

Chen, Y. S., \& Cheng, C. H. (2013). Hybrid models based on rough set classifiers for setting credit rating decision rules in the global banking industry. Knowledge-Based Systems, 39, 224-239.

Dias, J., \& Psico, J. (2008). O desempenho social das instituições de microfinanças em Moçambique. Economia Global E Gestão, 13(2), 4359.

Freitas, H., Oliveira, M., Saccol, A., \& Moscarola, J. (2000). O método de pesquisa survey. Revista de Administração, v. 35(3), 105-112.

Ghosh, S., \& Van Tassel, E. (2013). Funding microfinance under asymmetric information. Journal of Development Economics, 101(1), 8-15.

Gil, A. C. (1999). Métodos e Técnicas de Pesquisa Social. São Paulo: Atlas (5. ed.). São Paulo: Editora Atlas.

Hair, J., Anderson, R., \& Tatham, R. (2005). Análise multivariada de dados (5. ed.). Porto Alegre: Bookman.

Haya, C. C. (2005). Tourism, Microfinance and Poverty Alleviation.

Hermes, N., Lensink, R., \& Meesters, A. (2008). Outreach and Efficiency of Microfinance Institutions. SSRN Electronic Journal, 39(6), 1-29.

Hodgman, D. (1960). Credit risk and credit rationing. The Quarterly Journal of Economics, 74(2), 258-278.

Hulme, D., \& Mosley, P. (1996). Finance Against Poverty Volumes 2.
(Routledge, Ed.), Project ... (1 $\left.{ }^{\mathrm{a}}\right)$. New York: Routledge.

Hulme, D., \& Mosley, P. (2005). Finance Against Poverty:; Volume 1. New York: Routledge.

Instituto Brasileiro de Administração Municipal. (2001). Relatório final do Projeto: perspectivas de expansão das microfinanças no Brasil: marco legal, capitalização e tecnologia. Rio de Janeiro.

Jaffee, D., \& Russell, T. (1976). Imperfect information, uncertainty, and credit rationing. The Quarterly Journal of Economics, 90(4), 651-666.

Kraychet, E. S., \& de Oliveira Santos, N. (2005). O Banco Mundial e o desenvolvimento das microfinanças em países da periferia capitalista (Tese de doutoramento - Doutorado em Administração) - Escola de Administração, Universidade Federal da Bahia, Salvador)

Ledgerwood, J. (1999). Microfinance Handbook. Sustainable Banking with the Poor, World Bank, ... (Segunda Ed). Washington: The World Bank.

Lima, S. (2009). Microcrédito como política de geração de emprego e renda. Revista Do BNDES, 32, 47-75. Recuperado em 10 de oututro, 2013 dehttp://www.bndespar.gov.br/SiteBNDES/export/sites/default/bndes_pt /Galerias/Arquivos/conhecimento/revista/rev3202.pdf

Martins, P. H. (2008). Marco Legal das Microfinanças no Brasil. Brasília.

Martins, P. H., Winograd, A., \& Salles, R. C. (2002). Manual de Regulamentação das Microfinanças: Programa de Desenvolvimento Institucional. Rio de Janeiro.

Mia, M. A., \& Chandran, V. G. R. (2016). Measuring financial and social outreach productivity of microfinance institutions in Bangladesh. Social Indicators Research, 127(2), 505-527.

Morduch, J. (1999). The microfinance promise. Journal of economic literature, 37(4), 1569-1614

Neri, M. C. (2008). Microcrédito: o mistério nordestino e o Grameen brasileiro: perfil e performance dos clientes do CrediAmigo. Rio de Janeiro: FGV Editora.

Neri, M. C. (2012). Microempresários Urbanos Nordestinos, Favelas Cariocas e o Programa CrediAmigo. Rio de Janeiro.

Ribeiro, C. T., \& Carvalho, C. E. (2006). Do microcrédito às microfinanças: desempenho financeiro, dependência de subsídios e fontes de financiamento: uma contribuição à análise da experiência brasileira $\left(1^{\mathrm{a}}\right)$ SÃO PAULO: FAPESP.

Rodríguez, F. J. G., \& Perdomo, Y. D. (2011). Los microcréditos como herramienta de desarrollo: revisión teórica y propuesta piloto para el África Subsahariana. CIRIEC-España, Revista de Economía Pública, Social y Cooperativa, 70, 101-126. Rogaly, B. (1996). Micro-finance evangelism, "destitute women", and the hard selling of a new anti-poverty formula. Development in Practice, 6(2), 100-112.

Schrickel, W. K. (1995). Análise de Crédito: concessão e gerência de empréstimos (2nd ed.). São Paulo: Atlas.

Serrano-Cinca, C., \& Gutiérrez-Nieto, B. (2014). Microfinance, the long tail and mission drift. International Business Review, 23(1), 181-194.

Serviço Brasileiro de Apoio às Micro e Pequenas Empresas. (2011). Taxa de Sobrevivência das Empresas no Brasil. Brasília.

Silva, J. P. da. (2006). Gestão e análise de risco de crédito (5th ed.). São Paulo: Atlas.

Soares, M. M., \& Melo Sobrinho, A. D. (2008). Microfinanças - O Papel do Banco Central do Brasil e a Importância do Cooperativismo de Crédito. (2a , Ed.). Brasilia: Banco Central do Brasil.

Van der Sterren, J. (2008). Financial markets, microfinance and tourism in developing countries. ARA (Caribbean) Journal of Tourism Research, 2(4), 35-43.

Stiglitz, J., \& Weiss, A. (1981). Credit rationing in markets with imperfect information. The American Economic Review, 71(3), 393-410.

Wright, G. (1999). Examining the impact of microfinance services-increasing income or reducing poverty?. Small Enterprise Development, 10(1), 3847. 